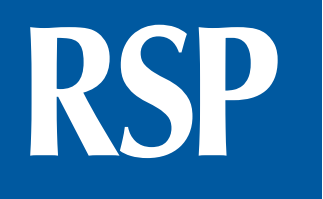

http://www.rsp.fsp.usp.br/

Revista de Saúde Pública

\title{
Background noise analysis in urban airport surroundings of Brazilian cities, Congonhas Airport, São Paulo
}

\author{
Fabio Scatolini', Cláudio Jorge Pinto Alves' \\ ' Programa de Pós-Graduação em Engenharia de Infraestrutura Aeronáutica. Departamento de Engenharia Civil. \\ Instituto Tecnológico da Aeronáutica. São José dos Campos, SP, Brasil
}

\begin{abstract}
OBJECTIVE: To perform a quantitative analysis of the background noise at Congonhas Airport surroundings based on large sampling and measurements with no interruption.

METHODS: Measuring sites were chosen from 62 and 72 DNL (day-night-level) noise contours, in urban sites compatible with residential use. Fifteen sites were monitored for at least 168 hours without interruption or seven consecutive days. Data compilation was based on cross-reference between noise measurements and air traffic control records, and results were validated by airport meteorological reports. Preliminary diagnoses were established using the standard NBR-13368. Background noise values were calculated based on the Sound Exposure Level (SEL). Statistic parameters were calculated in one-hour intervals.
\end{abstract}

RESULTS: Only four of the fifteen sites assessed presented aircraft operations as a clear cause for the noise annoyance. Even so, it is possible to detect background noise levels above regulation limits during periods of low airport activity or when it closes at night.

CONCLUSIONS: All the sites monitored showed background noise levels above regulation limits between 7:00 and 21:00. In the intervals between 6:00-6:59 and 21:00-22:59 the noise data, when analyzed with the current airport operational characteristics, still allow the development of additional mitigating measures.

Correspondence:

Fabio Scatolini

Rua Antônio Basílio, 519/403 Tijuca 20511-190 Rio de Janeiro, RJ, Brasil

E-mail: fabio.scatolini@gmail.com

Received: 26 May 2015

Approved: 29 Nov 2015

How to cite: Scatolini F, Alves CJP. Background noise analysis in urban airport surroundings of Brazilian cities, Congonhas Airport, São Paulo. Rev Saude Publica. 2016;50:69.

Copyright: This is an open-access article distributed under the terms of the Creative Commons Attribution License, which permits unrestricted use, distribution, and reproduction in any medium, provided that the original author and source are credited.
DESCRIPTORS: Airports. Noise, Transportation, adverse effects. Noise Measurement. Sound Contamination. Urban Area. 


\section{INTRODUCTION}

The noise generated by aircraft operating in urban airports causes great dissatisfaction and annoyance for people who live nearby. The indirect physiological effects of this anthropic activity, mainly those interfering in the nocturnal sleep, force important airports in Europe to interrupt their operations for a few hours during the night, such as the Frankfurt in Germany, the Gatwick in United Kingdom, among others. Competition between economic and environmental impacts is not rare ${ }^{9,21}$, leading airport authorities to try to concialiate both issues ${ }^{12,13,16}$.

Continuous exposure to average noise levels with intensity above $65 \mathrm{~dB}(\mathrm{~A})$ can cause several psychophysiological disorders ${ }^{10}$, regardless of age, such as sleep disorders, decreased work performance, high blood pressure, and aggravation of vascular diseases ${ }^{3,19}$.

However, since noise emission limits became more restrictive for civil aircraft in 2001 by the International Civil Aviation Organization (ICAO) ${ }^{\mathrm{a}}$, the non-aircraft noise, also known as "background noise", has gained importance to determine diagnosis of noise pollution in airport surroundings, regarding the designing (or development) of the respective mitigating measures. In tropical countries such as Brazil, the intensity of urban noise in general can be very high ${ }^{14}$. In European countries, the opposite can be easily found ${ }^{1}$.

Although the aircraft noise may not, in the short term, be significantly reduced at the source, noise monitoring systems in airports are still a useful tool to improve environmental policies in airport administrations ${ }^{20}$. Such systems help the identification of daily critical periods related to the residents' annoyance ${ }^{17}$, seeking to adjust curves, noise contours, or noise zoning plans, obtained by mathematical models and annoyance metrics ${ }^{11}$. They also help the air traffic control to develop trajectories of little annoyance ${ }^{15}$.

The metrics that determine sound annoyance caused by aircraft generally do not consider the background noise, which frequently results in the determination of the most problematic areas that are inconsistent with the local reality. In fact, even the document ICAO $9829^{\mathrm{b}}$ that presents and describes the "Balanced Approach" concept - widely accepted and supported by all the actors involved in the problem - does not mention background noise. Thus, these discrepancies have been better managed with noise monitoring systems, whose associated compiled data and opinion surveys, applied to residents ${ }^{8}$, often provide a good view of the problem.

The objective of this study was to evaluate, in a more objective manner, the background noise related to urban airports operations in Brazil. We proposed a procedure to identify aircraft noise events, considering the total environmental noise and dismissing the use of surveys. The Congonhas Airport (São Paulo, SP) was used as a case study because, even being one of busier Brazilian airports, it remains closed for seven hours a day since 1995, working in the other hours of the day near to its maximum capacity. An alternative methodology was adopted (mobile collectors) for the necessary measurements in order to optimize both the equipment use and the sampling size, without affecting accuracy.

${ }^{a}$ International Civil Aviation Organization. International Standards and Recommended Practices. Annex 16: environmental protection. Vol. 1: Aircraft noise. Quebec: International Civil Organization; 2001.

b International Civil Aviation Organization. DOC 9829: Balanced approach guidance. Montreal: International Civil Aviation Organization; 2007.

\section{METHODS}

Initially, the study's range was established, from the Congonhas Airport, for monitoring purposes. Noise contours were used according to DNL metric (day-night-level), formally adopted by the National Civil Aviation Agency (ANAC) according to the Brazilian Civil Aviation Regulation 161 (RBAC 161). Using the Integrated Noise Model software (INM) of the Federal Aviation Administration, United States of America (FAA), two closed curves were calculated and drawn around the airport limits, representing the union of points with the same DNL (Figure 1). 
cAgência Nacional de Aviação Civil. RBAC 161: planos de zoneamento de ruído. Brasília (DF): Agência Nacional de Aviação Civil; 2012. Preconiza valores de LDN para as curvas interna e externa de, respectivamente, 75 e 65 . (cited 2015 jan 15). Available from: http://www.anac.gov.br/assuntos/ legislacao/legislacao-1/rbha-erbac/rbac/rbac-161-emd-01/@@ display-file/arquivo_norma/ RBAC161EMD01.pdf

${ }^{\mathrm{d}}$ Associação Brasileira de Normas Técnicas. NBR-10151: Avaliação do ruído em áreas habitadas visando o conforto da comunidade. Rio de Janeiro (RJ): Associação Brasileira de Normas Técnicas; 2000.

eAssociação Brasileira de Normas Técnicas. NBR-13368: Ruído aeronáutico - Monitoramento. Rio de Janeiro (RJ): Associação Brasileira de Normas Técnicas; 1995.

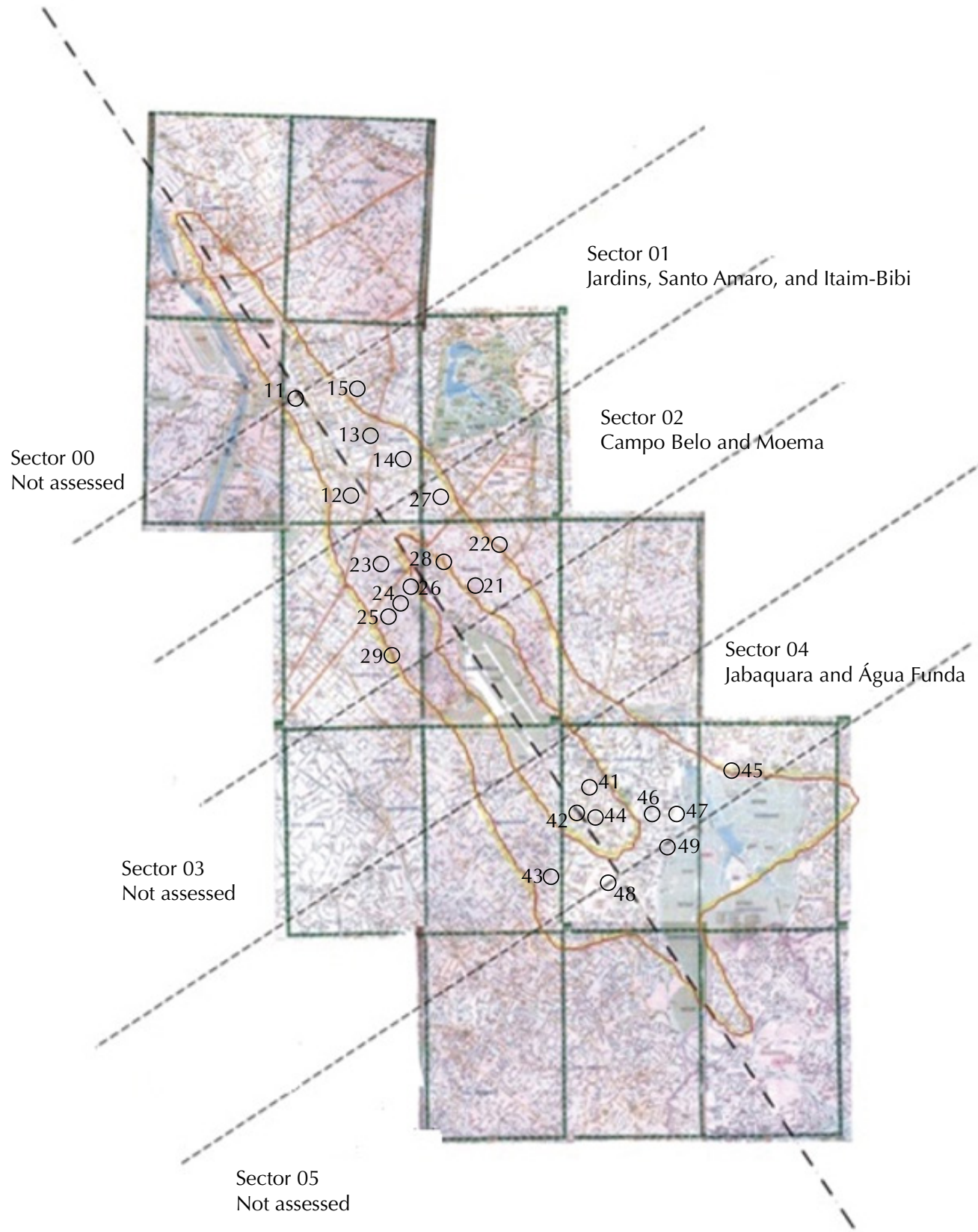

Graphic scale

$0 \quad 2,000 \mathrm{~m}$

Figure 1. Noise contours for Congonhas Airport (62 and $72 \mathrm{DNL}$ ), and location of the 23 pre-selected sites for noise measurement.

The values of the internal and external curves are, respectively, 72 and 62 DNL. By the metric's definition, these values are equivalent to simulated noise levels of 67.8 and $57.8 \mathrm{LEq}$ (equivalent continuous sound level in $\mathrm{dB}(\mathrm{A})$ ), respectively, in a period of 24 hours and produced exclusively by aircraft. These values ( 72 and $62 \mathrm{DNL}$ ), although different than what $\mathrm{ANAC}^{\mathrm{c}}$ adopts for Noise Zoning Plans at airports, are more compatible with the national regulation ${ }^{\mathrm{d}, e}$, which establish "significant" sound impact to measured values above $3 \mathrm{~dB}(\mathrm{~A})$ from the allowed limit or the background noise (whichever is louder).

Figure 1 shows a map with noise contours produced for the study.

After the aviation accident occurred in July 2007 (TAM 3054), the allowed number of aircraft operations at the Congonhas Airport was limited to 34 per hour and can reach 
40 in peak hours (early morning and late afternoon), although the infrastructure installed comprise up to 50 operations per hour. The INM was fed with relevant information about air traffic, with the intent to emulate the maximum capacity established by the regulations (210,000 operations/year), considering that $12.0 \%$ of the operations occur at night (between 22:00 and 6:59), because the airport closes every day at 23:00 and reopen at 6:00.

Twenty-three sites were pre-selected using maps that presented the detailed street layout and were visited before the beginning of measurements. Then, fifteen were chosen to receive the measuring equipment, taking particularly into account the prevalence of residential use on the surroundings and the potential exposure to noise. The perimeter of $62 \mathrm{DNL}$ was subdivided into six "sectors", drawing five lines orthogonal to the airport runway axis, distant each other by one runway length (approximately 2,000 meters). The sectors 00, 03, and 05 were previously disregarded for the study, either because the area's relief favors a strong aircraft noise attenuation or because the aircraft fly over the homes at higher altitudes. Within the sectors 01,02 , and 04 , the fifteen measuring sites were chosen in a similar way to that described by Carvalho et al. ${ }^{5}$ (2014), who adopted the identification of "sensitive points" (activities of public or collective nature, compatible with the residential use, such as education and health).

The measurements were carried out between May and October 2009. Each site was monitored for at least seven consecutive days without interruption. The data obtained on that occasion still represent the current situation, since neither the urban organization nor the operational airport characteristics showed modifications that may interfere with the noise sources behavior in the surrounding areas. The airport continues to operate since 2007 with the same characteristics that limit its operation in parameters inferior to both the demand and the installed capacity. Vehicle traffic, in turn, will only suffer modifications that might reduce the respective noise emission when completed all the infrastructure works that are in progress at the moment, particularly the Monorail Line 17-Gold - Morumbi-Jabaquara.

Five noise monitoring stations with meters and analyzers Larson Davis 824A plus accessories were used, which operate without permanent assistance or presence, resulting in three measuring campaigns, of five sites each. The meters were programmed to record all the measurement parameters derived from the $\mathrm{dB}(\mathrm{A})$ allowed by the equipment $\mathrm{f}^{\mathrm{f}}$, as well as to store all instantaneous noise samples, taken at intervals of one second, to allow the elaboration of other parameters calculations, when necessary.

The equipment also has been programmed to detect the characteristics of duration and loudness of aircraft overflights (takeoffs and landings), in each site, and to register the noise produced separately from the total noise measurement, which are very peculiar when compared with other mobile sources. Each record of this kind, called "event" by the memory of the equipment, had its instantaneous taken at every second, allowing the calculation of LEq and, mainly, the Sound Exposure Level (SEL) ${ }^{7}$ of each overflight, detected by crossing the data with the Control Tower reports, provided by the Airport administrator (Infraero). As Congonhas is an airport that operates a little diversified fleet, so that more elaborate segregation processes are not required ${ }^{2,6}$.

The SEL values of aircraft events were accumulated in periods of one hour and, after measurements, subtracted logarithmically from the SEL values of total noise, to obtain the background noise of each period. We considered the aircraft events recorded between 6:00 and 12:00, on Sunday, the most relevant results, because this period tends to be the one with less traffic noise influence in the Congonhas Airport vicinities. This leads to a better isolation of aircraft events, resulting in a more accurate calculation of the respective SEL and that, in turn, can be extrapolated to other periods in the remaining days of the week, when the background noise rises, making more difficult the noise events identification and

${ }^{\mathrm{f}}$ Sound level (LEq), sound exposure level (SEL), percentile levels (Ln), maximum (Lmax) and minimum sound level (Lmin), among others. segregation. As the operation of small aircraft (with capacity up to 30 passengers) is limited to only four operations per hour (landings plus takeoffs), for them, the same SEL average value was considered among the ones registered by the noisiest aircraft models. Approximately 
Table. Summary of monitoring results - Congonhas Airport.

\begin{tabular}{cccccccc}
\hline Measuring site & $\begin{array}{c}\text { No. of } \\
\text { hours of } \\
\text { the sample }\end{array}$ & $\begin{array}{c}\text { LEq of total } \\
\text { noise } \\
(\mathrm{dB} / \text { hour })\end{array}$ & $\begin{array}{c}\text { Min LEq-max } \\
\mathrm{LEq}(\mathrm{dB}-\mathrm{hour})\end{array}$ & $\begin{array}{c}\text { Average of } \\
\text { overflights } \\
\text { per hour }\end{array}$ & $\begin{array}{c}\text { LEq of } \\
\text { background } \\
\text { noise } \\
(\mathrm{dB} / \mathrm{hour})\end{array}$ & $\begin{array}{c}\text { Average of } \\
\text { nominal } \\
\text { differences } \\
(\mathrm{dB})\end{array}$ & Remarks \\
\hline
\end{tabular}

\section{Sector 01}

\begin{abstract}
11 - Anne Frank
Municipal Library

13 - São Germano

Clinic

12 - EMEF Mary

Aux. D’Alquimin
\end{abstract}

Bastos

Sector 02

\section{3 - EE Napoleão \\ de Carvalho Freire \\ 27 - Franciscano}

Nossa Senhora

Aparecida School

25 - Pinheiros

Orthopedic Clinic

21 - Brandão

Educational Center

118

62.6

16

61.8

0.8

\begin{abstract}
26 - Augusto
Laranja School
\end{abstract}

28 - Ibirapuera

University

118

63.8

16

62.5

Chiquinha

Rodrigues

$\begin{array}{cc}\text { No. of } & \begin{array}{c}\text { Arithmetic } \\ \text { mean of the } \\ \text { Measuring site }\end{array} \\ \text { the sample } & \begin{array}{c}\text { total noise } \\ \text { (dB/hour) }\end{array}\end{array}$

$52.3-69.1$

60.7

Min avg - Max avg (dB-hour)
55.8

57.3

58.1

56.5

ZERO

4.8
Sector 04

\section{8 - EMEF}

Armando de

Arruda Pereira

41 - Faculdade

Colégio Montessori

70

65.7

44 - Nossa

Senhora de Lourdes

Hospital

51

61.3

$56.7-68.1$

17

59.2

45 - Botanical

Institute

70

53.7

41.2-63.1

16

ND

0

49 - Nossa

Senhora das Graças

School
21

67.1

$\begin{array}{ccc}\begin{array}{c}\text { Average of } \\ \text { overflights } \\ \text { per hour }\end{array} & \begin{array}{c}\text { Arithmetic } \\ \text { mean of the } \\ \text { background } \\ \text { noise } \\ \text { (dB/hour) }\end{array} & \begin{array}{c}\text { Average of } \\ \text { nominal } \\ \text { differences }\end{array}\end{array}$

Exclusively residential area.

Background noise $1 \mathrm{~dB}(\mathrm{~A})$ above limit.

Area of mixed use. Total noise in the limit allowed.

Site right below the runway axis.

Area of mixed use. Moderate to intense traffic.

Exclusively residential area.

Background noise $1.5 \mathrm{~dB}(\mathrm{~A})$ above the limit.

Measured during school winter recess. Area of mixed use. Aircraft noise is blocked by nearby buildings.

Area of mixed use. Cobblestones pavement. Moderate to intense traffic.

Area of mixed use. Relief favorable

to reduction of aircraft noise.

Background noise $1.8 \mathrm{~dB}(\mathrm{~A})$ above the limit.

Exclusively residential area. Site right below the runway axis. Background noise $2.4 \mathrm{~dB}(\mathrm{~A})$ above the limit.

Area of mixed use with commercial predominance. Intense bus traffic. Background noise $2.5 \mathrm{~dB}(\mathrm{~A})$ above the limit.

Area of mixed use. Cobblestones pavement. Moderate to intense traffic.

\footnotetext{
EMEF: City School of Basic Education; EE: State High School; Min avg: average of the instantaneous minimum levels; Max avg: average of the instantaneous maximum levels; ND: not detected
} 
$80.0 \%$ of the air traffic is held with 320 series Airbus aircraft and the 737 NG Boeing family, very similar in size and noise emission ${ }^{\mathrm{g}}$.

The sampling period of seven consecutive days was chosen because it captures all relevant events in a city's routine. After this period, the environmental noise levels tend to repeat. Thus, it is possible to achieve good preliminary diagnostics without extending the measurements. Data analysis of noise from each monitored site considered the regulations of the Brazilian National Standards Organization (ABNT) $)^{\mathrm{e}}$, which diagnoses the situation without using opinion surveys (more subjective).

Finally, the respective Meteorological Aerodrome Reports (METAR), elaborated by the air traffic control, were analyzed to exclude from the samplings the periods that showed bad weather conditions for the noise measuring by NBR $10151^{\mathrm{d}}$ (wind above $9 \mathrm{~km} / \mathrm{h}$ or rain) or short-term reversals in the takeoff and landing path directions.

\section{RESULTS}

The Table summarizes the results for the fifteen sites monitored. Each site, of the 168 hours effectively carried out, obtained an average of 70 valid measurement hours. Two factors reduced the samples: the daily closing period of the airport runway and the periods of bad weather conditions (rain or wind that reversed the runway operation direction). Among the valid measurements it was observed that the background noise showed values above the ones recommended by national regulations in seven of the fifteen sites (points 11,21, 25, 28, 29, 48, and 49). These sites are near major avenues and are exposed to significant noise, generated by cars and motorcycles seeking alternative paths to main roads, usually congested.

In the eight remaining sites, four showed differences between aircraft noise and background noise lower than $3 \mathrm{~dB}(\mathrm{~A})$ (points 13, 27, 41, and 45), caused by the existence of obstacles to aircraft noise propagation, by presenting favorable relief to attenuation or because the aircraft fly over the site at high altitudes. A distinct aircraft contribution to the annoyance was found only in the last four sites, due to their proximity to the airfield or the low altitude of overflights (points 12, 23, 26, and 44).

\section{DISCUSSION}

Even in the sites where there was major contribution of aircraft noise to the total noise, it was observed that, between 9:00 and 21:00 pm, the one-hour LEq for total noise showed values above $65 \mathrm{~dB}(\mathrm{~A})$, with the one-hour $\mathrm{LEq}$ for background noise above $60 \mathrm{~dB}(\mathrm{~A})$. This happens due to the vehicle traffic noise (which increases with the number of vehicles in the streets), especially motorcycles ${ }^{\text {h }}$. From 2001 to 2012, the number of cars and light utility vehicles licensed in São Paulo doubled, while the motorcycle amount was multiplied by four. Another relevant fact is that the motorcycle models up to $175 \mathrm{cc}$ (the most sold ones) can emit $3 \mathrm{~dB}(\mathrm{~A})$ more noise than carsi. Figure 2 shows the one-hour LEq of total noise in one of the four sites with the greatest contribution to aircraft noise (site \#23). It was observed that, even on Sundays, the total average noise was above the regulation limits ( $50 \mathrm{~dB}(\mathrm{~A})$ between 7:00 and 21:59 and $45 \mathrm{~dB}(\mathrm{~A})$ between 22:00 and 6:59).

A strong decrease in the total environmental noise can be observed after 21:00 in almost all sites measured. This phenomenon can be explained not only by the airport activity reduction (between 21:00 and 23:00), but also by the decrease of vehicle traffic on alternative routes, even though the main avenues present high volumes. At night, drivers tend to stay in the main corridors for security reasons (better lighting, policing, etc.), which shows the potential auxiliary role of airport noise monitoring to both determine noise pollution in relation to 


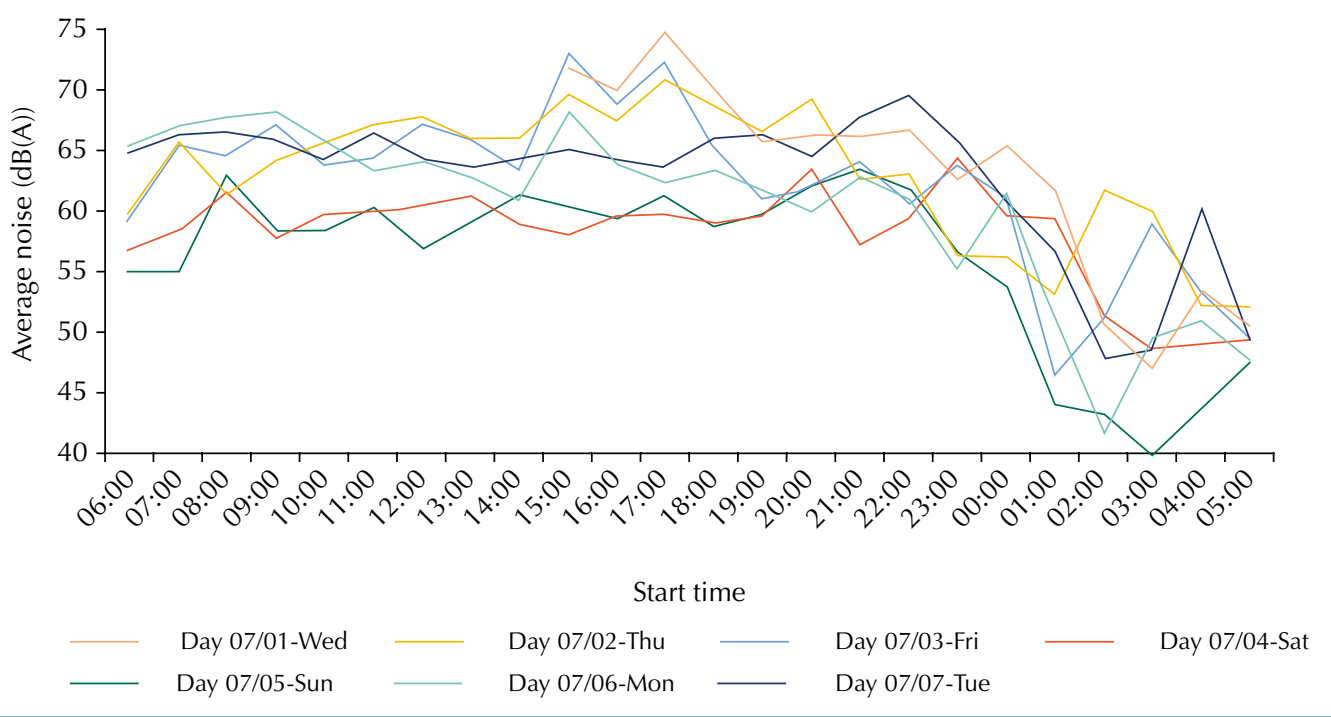

Figure 2. Behavior of one-hour LEq for total environmental noise (aircraft + background) in site \#23.

the day period ${ }^{4}$, and search the peculiar characteristic changes of the environmental noise within the airport closing limits ${ }^{17}$.

Thus, it was possible to observe interesting facts that make feasible to design additional mitigating measures, even at airports that already suffer high operational restrictions, such as Congonhas. In site \#23, separated to be discussed in this article, there is a public school in an exclusively residential area presenting low traffic noise. The accordance with the noise regulation limits was only complied between 1:00 and 6:00. As the airport activity ceases daily at 23:00, it is possible to infer that the background noise is high not only in this period, but also during the whole day.

On July 5th, 2009, Sunday, between 6:00 and 11:00, the equipment programming to detect aircraft events registered 31 occurrences with instantaneous levels above the environmental noise level for more than 22 consecutive seconds, which were assigned to aircraft in landing procedure. Considering all the valid sampling, an average of 14 overflights were recorded per hour, by calculating an average SEL dB(A) of 81.6 for each overflight and 59 hours of valid measurement. By subtracting the aircraft SEL in each valid monitoring hour from the respective total environmental SEL, and then dividing the result by 3,600 seconds, one finds the background noise LEq (average) shown in Figure 3.

The average background noise exceeds by $6 \mathrm{~dB}(\mathrm{~A})$ the regulation limit in many of the one-hour valid periods (Figure 3, green line), and the differences compared with the average total noise (Figure 3, blue line) are big (larger than $3 \mathrm{~dB}(\mathrm{~A})$ ), which means a strong influence of the airport operation on noise pollution, at this particular site. The highest differences between the total noise and the background noise were found in the airport closing limits, in the last two hours of operation at night (between 21:00 and 23:00) and mainly in the early morning (between 6:00 and 8:00), when the background noise is still low in intensity and the airport starts its operation with "full power."

Since 2007, Congonhas Airport's range is limited to attend destinations up to $1,000 \mathrm{~km}$, which favors turboprop aircraft operations, quieter and more efficient in fuel consumption. Although they take less passengers and payload than the B737 NG and A320 aircraft, it is possible to think about a fleet replacement in the last and first hours of the airport operation period, if there is a lower demand for transportation ${ }^{18}$. Consequently, the differences between aircraft noise and background noise would be reduced, thereby reducing the sound impact. In a higher or lower degree, this approximation between background and aircraft noise was present in the other fourteen sites monitored for this study. 


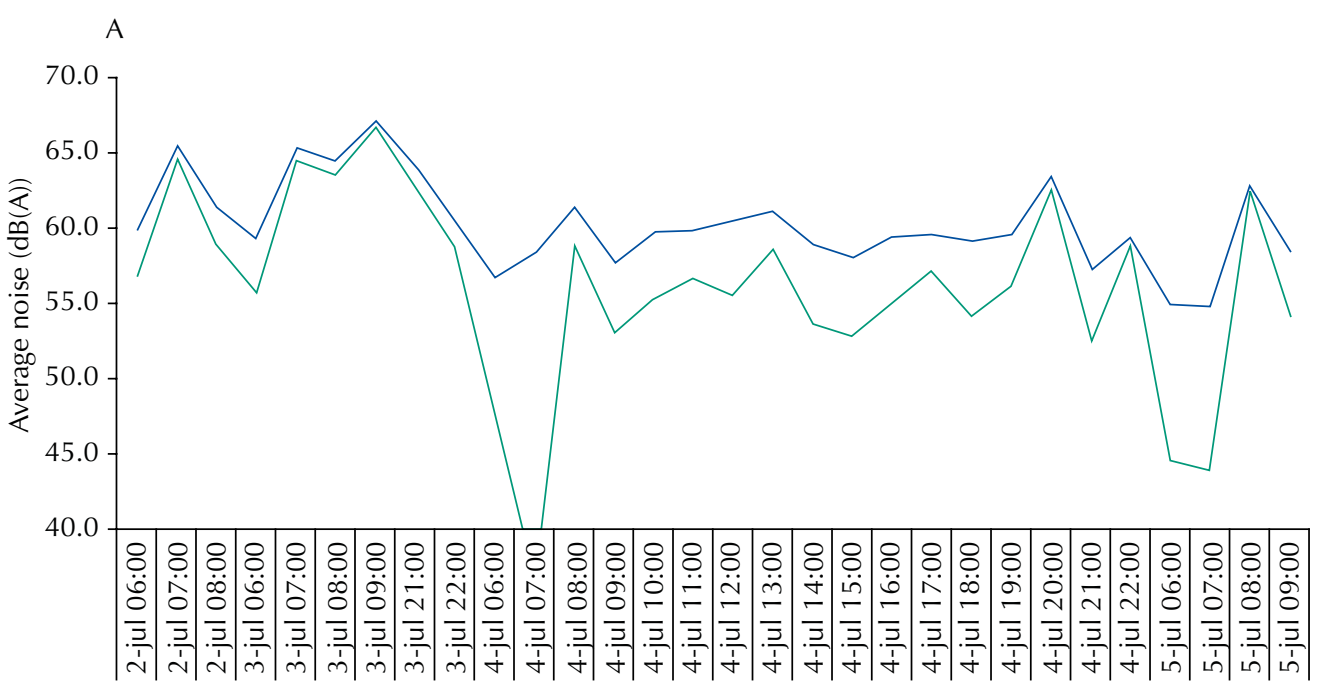

B

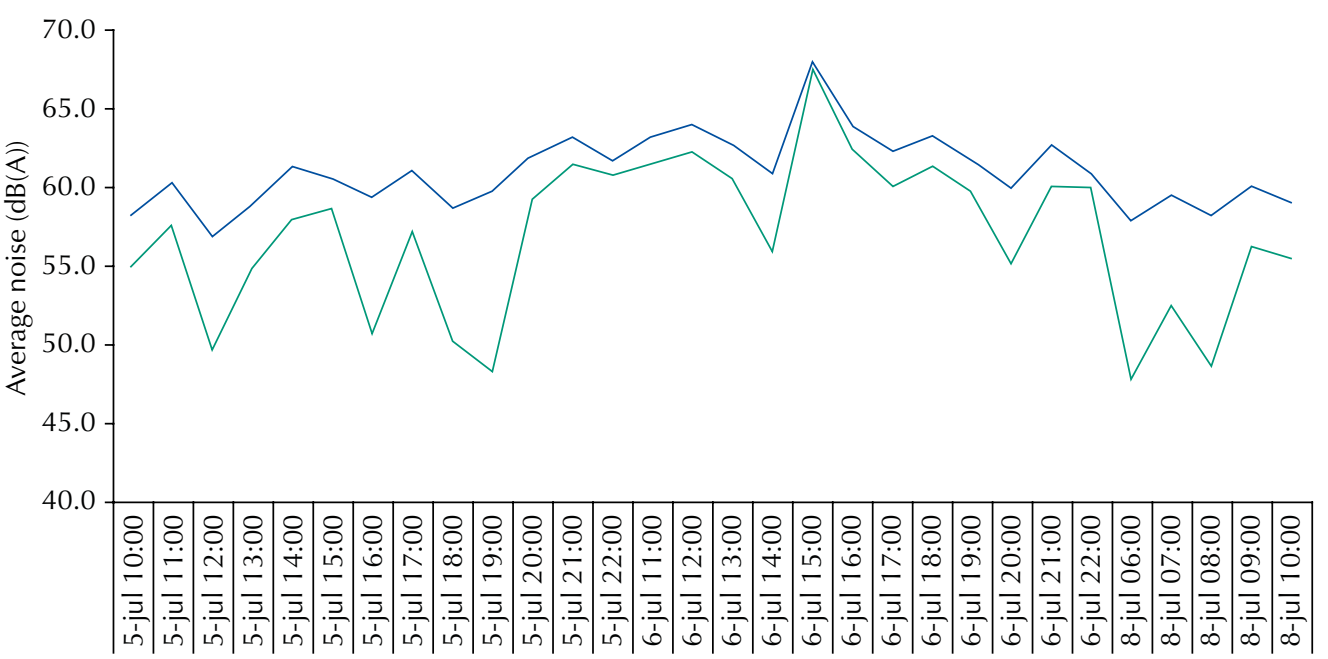

Start time of one-hour valid periods

Total noise

Background noise

Figure 3. Nominal differences between environmental noise and background noise (one-hour LEq) for the site $\# 23: 3 \mathrm{~A}$ - part 1, 3B - part 2 (discontinuous sampling).

Therefore, the way the background noise is in the Congonhas Airport surroundings, it is possible that this urban equipment operates between 7:00 and 21:00 in its current configuration, without generating higher sound impacts. This daily "window" remains independently of seasonal variations as occurs, for example, in South Korea ${ }^{12}$ and Poland ${ }^{14}$. Still, the diagnostic parameters recommended by NBR $13368^{\mathrm{e}}$ were efficient enough to dismiss the use of survey questionnaires applied to the population, which constitute more subjective sources of information.

However, the total environmental noise is a disturbing situation, because the national regulations of noise pollution are disrespected in almost all hours of the day, no matter the day of the week, being the airport open or closed. That means, even if the Congonhas Airport was "shut down" permanently, the problem of noise pollution would continue in its vicinities.

Much of the background noise registered is related to the increased circulation of motorcycles in the last ten years, which have been used by the inhabitants to replace deficient public transportation. This fact may spoil public health in several other aspects, because the regulation allows motorcycles to emit more noise and air contaminants than other vehicles. In addition, motorcycles are increasing emergency care costs, once the number of traffic accidents involving motorcycles also increased. It is, therefore, a vicious circle that contributes to degrade the population's health. 


\section{REFERENCES}

1. Arana M. Are urban noise pollution levels decreasing? J Acoust Soc Am. 2010;127(4):2107-9. DOI:10.1121/1.3337228

2. Asensio C, Ruiz M, Recuero M. Real -time aircraft noise likeness detector. Appl Acoust. 2010;71(6):539-45. DOI:10.1016/j.apacoust.2009.12.005

3. Babisch W, Ising H, Gallacher JEJ. Health status as a potential effect modifier of the relation between noise annoyance and incidence of ischaemic heart disease. Occup Environ Med. 2003;60(10):739-45. DOI:10.1136/oem.60.10.739

4. Brooker P. Aircraft noise annoyance estimation: UK time-pattern effects. Appl Acoust. 2010;71(7):661-7. DOI:10.1016/j.apacoust.2010.01.010

5. Carvalho LA, Slama JG, Nassi CD. A complementary metric to define a buffer zone in Brazilian airports. J Transport Literature. 2014;8(4):316-28. DOI:10.1590/2238-1031.jtl.v8n4a12

6. Genescà M, Romeu J, Pamies T, Sanches A. Real-time aircraft fly-over noise discrimination. I Sound Vibrat. 2009;323(1-2):112-29. DOI:10.1016/j.jsv.2008.12.030

7. Harris CM. Handbook of noise control. 2nd ed. New York: McGraw Hill; 1991. ch 34, 35, 38, 39.

8. Lim C, Kim J, Hong J, Lee S. Effect of background noise levels on community annoyance from aircraft noise. J Acoust Soc Am. 2007;123(2):766-71. DOI:10.1121/1.2821985

9. Lu C. The economic benefits and environmental costs of airport operations: Taiwan Taoyuan International Airport. J Air Transp Manage. 2011;17(6):360-3. DOI:10.1016/j.jairtraman.2011.02.006

10. Maschke C. Preventive medical limits for chronics traffic expose. Acustica. 1999;85:444-8. DOI:10.1121/1.426504

11. Mioduszewski P, Ejsmont JA, Grabowski J, Karpinski D. Noise map validation by continuous noise monitoring. Appl Acoust. 2011;72(8):582-9. DOI:10.1016/j.apacoust.2011.01.012

12. Morrell P, Lu CHL. Aircraft noise social cost and charge mechanisms - a case study of Amsterdam Airport Schiphol. Transp Res. Part D. 2000;5(4):305-20. DOI:10.1016/S1361-9209(99)00035-8

13. Nero G, Black JA. A critical examination of an airport noise mitigation scheme and an aircraft noise charge: the case of capacity expansion and externalities at Sydney (Kingsford Smith) airport., Transp Res. Part D. 2000;5:433-61. DOI:10.1016/S1361-9209(00)00010-9

14. Paz EC, Ferreira AMC, Zanin PHT. Estudo comparativo da percepção do ruído urbano. Rev Saude Publica. 2005;39(3):467-72. DOI:10.1590/S0034-89102005000300019

15. Prats X, Puig V, Quevedo J, Nejjari F. Multi -objective optimization for aircraft departure trajectories minimizing noise annoyance. Transp Res. Part C. 2010;18:975-89. DOI:10.1016/j.trc.2010.03.001

16. Püschel R, Evangelinos C. Evaluating noise annoyance cost recovery at Düsseldorf International Airport. Transp Res. Part D. 2012;17:598-604. DOI:10.1016/j.trd.2012.07.002

17. Quehl J, Basner M. Annoyance from nocturnal aircraft noise exposure: laboratory and field specific dose-response curves. J Environm Psicol. 2006;2692:127-40. DOI:10.1016/j.jenvp.2006.05.006

18. Scatolini F, Alves CJP, Eller RAG. Easing the concept "Balanced Approach" to airports with densely busy surroundings - The case of Congonhas Airport. Appl Acoust. 2016;105:75-82. DOI: 10.1016/j.apacoust.2015.11.017

19. Stansfeld SA, Matheson MP. Noise pollution: non-auditory effects on health. Br Med Bull. 2003;68(1):243-57. DOI:10.1093/bmb/ldg033

20. Suau-Sanchez P, Pallares-Barbera M, Paul V. Incorporating annoyance in airport environmental policy: noise, societal response and community participation. J Transp Geogr. 2011;19(2):275-84. DOI:10.1016/j.jtrangeo.2010.02.005

21. Yan HK, Wang N, Wei L, Qjang F. Comparing aircraft noise pollution and cost -risk Effects of inland and offshore airports: The case of Dalian International Airport, Dalian, China. Transp Res. Part D. 2013;24:37-43. DOI:10.1016/j.trd.2013.05.005

Authors' Contribution: Study design, data collection and analysis, preparation of the manuscript: FS. Review of the manuscript: CJPA. Both authors have approved the final version of the manuscript and are responsible for their content.

Conflict of Interest: The authors declare no conflict of interest. 